\title{
MITOTIC SEGREGATION IN POLYPLOID STRAINS OF SACCHAROMYCES CEREVISIAE
}

\author{
J. M. MACKINNON* and J. R. JOHNSTON \\ Department of Applied Microbiology, University of Strathclyde, \\ Glasgow, C.1, Scotiand
}

Received 2.ix.71

\section{INTRODUCTION}

THE rates of spontaneous mitotic recombination of several non-centromerelinked genes in diploid strains of Saccharomyces cerevisiae are relatively high (Thornton and Johnston, 1971). Mitotic segregation could therefore be the principal mechanism of change in the genetic composition of yeast cultures during prolonged growth, such as industrial continuous fermentations. Since many industrial strains of brewing yeast are thought to be polyploid (Emeis, 1961, 1963; Johnston, 1963, 1965), it is important to know the effect of ploidy upon mitotic stability. The results of investigating mitotic segregation in triploid and tetraploid strains of Saccharomyces cerevisiae are reported below.

\section{Materials AND methods}

\section{(i) Strains}

1. All strains were derived from a diploid strain, X190, which was constructed from strains received originally from $\mathrm{Dr} R$. K. Mortimer. Its genotype was:

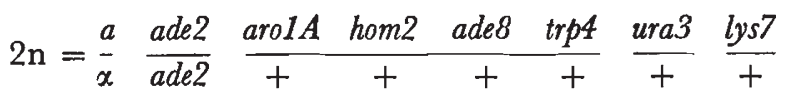

Symbols follow the convention proposed in the 1969 supplement to Microbial Genetics Bulletin.

2. An autotetraploid of strain X190 was isolated whose genotype was shown by genetic analysis to be a duplication of the diploid genome (see Results) and therefore:

$$
4 \mathrm{n}=\left[\begin{array}{lllllll}
\frac{a}{\alpha} & \frac{\text { ade2 }}{\text { ade2 }} & \frac{\text { arolA }}{+}+\text { hom }^{2} & \text { ade8 } & \text { trp4 } & \text { ura3 } & \text { lys } 7 \\
+ & + & \frac{2}{+}
\end{array}\right]^{2}
$$

This tetraploid strain was designated X190T. Throughout this paper, index numbers are used with genotypes to denote the number $(>1)$ of particular alleles present.

3. Triploid strains were then constructed from a diploid spore segregant of strain X190T crossed to haploid spore segregants of strain X190. Their genotypes as deduced by genetic analysis (see Results) were:

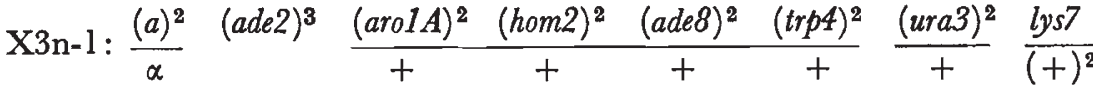

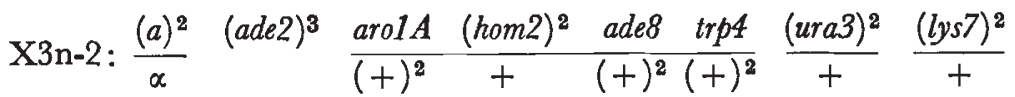

* Present address: Glaxo Laboratories Ltd., Ulverston, Lancs., England. 


\section{(ii) Media, culture methods and tetrad analysis}

Growth and diagnostic media, methods of growing and sporulating cultures and of meiotic genetic analysis were those already described (Thornton and Johnston, 1971).

\section{(iii) Detection of mitotic recombinants}

Strains homozygous for the ade2 mutation are red while those homozygous at both the ade2 and ade8 loci are white (Roman, 1956). Colonies of strain X190 are red but contain white sectors, almost all of which are ade8 mitotic recombinants, a majority of which are also trp4 recombinants (Johnston and MacKinnon, 1966). Revertants of ade2 are also white but are distinguishable from recombinants by their adenine-independence. Petite mutants of strain X190 also form white colonies but can be differentiated by their small size and inability to grow on glycerol medium (Ogur and St John, 1956).

\section{Results}

(a) Isolation and genetic analysis of tetraploid strain

While examining colonies of diploid strain X190, one colony containing pink sectors but no white sectors was observed. Upon culturing this colony and plating-out, none of a total of 1600 red colonies produced white sectors, showing that this character was heritable. Pink colonies with white sectors were also observed. The most likely possibility seemed that this variant would be a mitotic segregant homozygous for the Ade8 (wild-type) allele. Isolates from red colonies, later referred to as X190T, sporulated well and 110 asci were dissected. Of these, 45 had four viable spores and their tetrad analysis is shown in table 1 . In conjunction with the fact that some segregant cultures could sporulate but were unable to mate with $a$ and $\alpha$ haploid strains, while others could mate but not sporulate, these segregation ratios (table 1) suggest that strain X190T is tetraploid (Pomper, Daniels and McKee, 1954; Roman, Phillips and Sands, 1955).

TABLE 1

Segregation ratios of asci of strain X190T

No. of asci with segregation ratios $(+:-)$

\begin{tabular}{|c|c|c|c|}
\hline Gene & $4: 0$ & $3: 1$ & $2: 2$ \\
\hline $\operatorname{aro} 1 A$ & 16 & 23 & 6 \\
\hline hom 2 & 17 & 24 & 4 \\
\hline ade8 & 19 & 21 & 5 \\
\hline $\operatorname{trp} 4$ & 10 & 29 & 6 \\
\hline ura3 & 27 & 5 & 13 \\
\hline lys 7 & 24 & 18 & 3 \\
\hline
\end{tabular}

To investigate further the nature of strain X190T, five tetrads, in which each spore culture itself was able to sporulate, were subjected to "secondary" tetrad analysis. The detailed results of primary tetrad analysis of these asci (A-E) are given in table 2 and results of secondary analysis of the 20 segregant 
strains in table 3. These results show that spore cultures are diploid, confirm the tetrasomic nature of strain X190T for marked chromosomes, and taken with the reasonably high viability of spores, indicate that this strain is a complete tetraploid. The overall segregation ratios for ade 8 and trp4 in ascusB and for hom 2 in ascusG are irregular (table 3). These ratios show primary tetraploid segregation ratios of $3: 5$, indicative of non-reciprocal "conversion" (Refs. given by Fogel and Mortimer, 1970) in tetraploid meiosis.

TABLE 2

Tetrad analysis of five asci of strain X190T (all spore cultures able to sponalate)

Phenotype for gene

Ascus

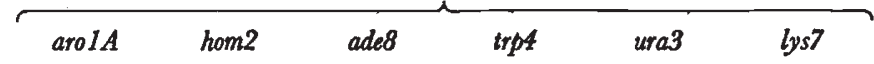

A

$\begin{array}{cc}- & + \\ + & + \\ + & + \\ + & + \\ 3: 1 & 4: 0\end{array}$

+
+
$3: 1$

+
+
$3: 1$

$\begin{array}{cc}+ & + \\ + & + \\ + & + \\ + & + \\ 4: 0 & 4: 0\end{array}$

B

$\begin{array}{cccc}+ & + & - & + \\ + & + & + & + \\ + & - & + & + \\ 3: 1 & 3: 1 & 2: 2 & 3: 1\end{array}$

C

Segregation ratio $3:$

$3: 1$

$3: 1$

+
+
+
+
+

$3: 1$

$\begin{array}{ll}+ & + \\ + & + \\ + & + \\ + & + \\ 4: 0 & 4: 0\end{array}$

D

\begin{tabular}{|c|c|c|c|c|c|c|}
\hline & & & & & & \\
\hline & + & + & + & + & + & + \\
\hline & + & + & + & + & + & + \\
\hline & - & - & + & + & + & $t$ \\
\hline gregation rati- & $3: 1$ & $3_{1}^{+}$ & $\stackrel{+}{+}: 0$ & $4: 0$ & $\stackrel{+}{4} \cdot 0$ & $4^{+}: 0$ \\
\hline
\end{tabular}

$\mathbf{E}$

$\begin{array}{rc} & + \\ & - \\ \text { Segregation ratio } & + \\ 2: 2 \\ \\ + \\ + \\ \text { Segregation ratio } & + \\ 4: 0\end{array}$

$$
\begin{aligned}
& + \\
& + \\
& + \\
& + \\
& 4: 0 \\
& + \\
& + \\
& + \\
& + \\
& 4: 0
\end{aligned}
$$

-
+
+
+
$3: 1$
+
+
+
+
$4: 0$

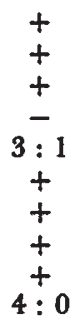

$\begin{array}{cc}- & - \\ + & + \\ + & - \\ - & + \\ 2: 2 & 2: 2 \\ + & + \\ + & + \\ + & + \\ + & + \\ 4: 0 & 4: 0\end{array}$

(b) Construction of triploid strains

As we wished to observe the frequency of mitotic segregation in triploid strains of constitution $\frac{(a d e 8)^{2}}{t}$ and $\frac{\text { ade } 8}{(+)^{2}}$, we decided to cross a common diploid strain to two different haploid strains. Since one parent had to be a diploid strain homozygous for one or other mating-type allele, it was not possible to determine this diploid genotype directly by sporulation and tetrad analysis, and indirect deduction was necessary. A (primary) segregant of strain X190T, X190T-S, was able to mate with an $\alpha$ haploid strain and had the phenotype ARO HOM TRP LYS ura ade, red. Since its colonies contained white sectors, its genotype for adenine genes was likely to be $\frac{\text { ade2 }}{\text { ade } 2} \frac{\text { ade8 }}{+}$. Segregant X190T-S was a member of a tetrad of X190T which 
TABLE 3

Segregation ratios of asci of spore cultures (Table 2) of strain X190T

\begin{tabular}{|c|c|c|c|c|c|c|}
\hline Ascus & arolA & hom 2 & ade8 & $\operatorname{trp4}$ & ura3 & bys7 \\
\hline Aggregate ratio & $\begin{array}{l}0: 4 \\
4: 0 \\
2: 2 \\
2: 2 \\
8: 8\end{array}$ & $\begin{array}{l}2: 2 \\
2: 2 \\
2: 2 \\
2: 2 \\
8: 8\end{array}$ & $\begin{array}{l}2: 2 \\
4: 0 \\
0: 4 \\
2: 2 \\
8: 8\end{array}$ & $\begin{array}{l}2: 2 \\
4: 0 \\
0: 4 \\
2: 2 \\
8: 8\end{array}$ & $\begin{array}{l}2: 2 \\
2: 2 \\
2: 2 \\
2: 2 \\
8: 8\end{array}$ & $\begin{array}{l}2: 2 \\
2: 2 \\
2: 2 \\
2: 2 \\
8: 8\end{array}$ \\
\hline Aggregate ratio & $\begin{array}{l}2: 2 \\
2: 2 \\
0: 4 \\
4: 0 \\
8: 8\end{array}$ & $\begin{array}{l}2: 2 \\
2: 2 \\
0: 4 \\
4: 0 \\
8: 8\end{array}$ & $\begin{array}{l}0: 4 \\
2: 2 \\
4: 0 \\
0: 4 \\
6: 10\end{array}$ & $\begin{array}{l}2: 2 \\
2: 2 \\
2: 2 \\
0: 4 \\
6: 10\end{array}$ & $\begin{array}{l}2: 2 \\
2: 2 \\
2: 2 \\
2: 2 \\
8: 8\end{array}$ & $\begin{array}{l}2: 2 \\
2: 2 \\
2: 2 \\
2: 2 \\
8: 8\end{array}$ \\
\hline Aggregate ratio & $\begin{array}{l}2: 2 \\
2: 2 \\
0: 4 \\
4: 0 \\
8: 8\end{array}$ & $\begin{array}{l}2: 2 \\
2: 2 \\
0: 4 \\
2: 2 \\
6: 10\end{array}$ & $\begin{array}{l}2: 2 \\
2: 2 \\
2: 2 \\
2: 2 \\
8: 8\end{array}$ & $\begin{array}{l}2: 2 \\
2: 2 \\
2: 2 \\
2: 2 \\
8: 8\end{array}$ & $\begin{array}{l}2: 2 \\
2: 2 \\
2: 2 \\
2: 2 \\
8: 8\end{array}$ & $\begin{array}{l}2: 2 \\
2: 2 \\
2: 2 \\
2: 2 \\
8: 8\end{array}$ \\
\hline Aggregate ratio & $\begin{array}{l}4: 0 \\
0: 4 \\
0: 4 \\
4: 0 \\
8: 8\end{array}$ & $\begin{array}{l}2: 2 \\
2: 2 \\
2: 2 \\
2: 2 \\
8: 8\end{array}$ & $\begin{array}{l}0: 4 \\
4: 0 \\
2: 2 \\
2: 2 \\
8: 8\end{array}$ & $\begin{array}{l}2: 2 \\
2: 2 \\
4: 0 \\
0: 4 \\
8: 8\end{array}$ & $\begin{array}{l}0: 4 \\
4: 0 \\
4: 0 \\
0: 4 \\
8: 8\end{array}$ & $\begin{array}{l}0: 4 \\
4: 0 \\
0: 4 \\
4: 0 \\
8: 8\end{array}$ \\
\hline Aggregate ratio & $\begin{array}{l}2: 2 \\
2: 2 \\
2: 2 \\
2: 2 \\
8: 8\end{array}$ & $\begin{array}{l}2: 2 \\
2: 2 \\
2: 2 \\
2: 2 \\
8: 8\end{array}$ & $\begin{array}{l}2: 2 \\
2: 2 \\
2: 2 \\
2: 2 \\
8: 8\end{array}$ & $\begin{array}{l}2: 2 \\
2: 2 \\
2: 2 \\
2: 2 \\
8: 8\end{array}$ & $\begin{array}{l}2: 2 \\
2: 2 \\
2: 2 \\
2: 2 \\
8: 8\end{array}$ & $\begin{array}{l}2: 2 \\
2: 2 \\
2: 2 \\
2: 2 \\
8: 8\end{array}$ \\
\hline
\end{tabular}

gave primary segregation ratios for markers aro1 $A$, hom $2, \operatorname{trp} 4$ and $\operatorname{lys} 7$ of $4: 0,4: 0,3: 1$ and $3: 1$, respectively. It was likely therefore that its genotype was $\frac{\operatorname{arolA}}{+} \frac{\text { hom } 2}{+}$ and probable $\left(\mathrm{P}=\frac{2}{3}\right)$ that it was also $\frac{\operatorname{trp4}}{+}$.

The diploid strain, X190T-S, was crossed with two haploid segregants of strain X190 of genotype: X190-S1 $\alpha$ aro1A hom 2 ade8 trp4 ade2 Ura3 Lys7 and X190-S2 $\propto$ Aro1A hom2 Ade8 Trp4 ade2 Ura3 lys7. Triploid hybrids were selected as colonies on minimal + adenine medium and designated X3n-1 and X3n-2. Four colonies of each hybrid were isolated and these sporulated well. This proved that none were ura3 revertants of strain X190T-S since these would have been $\frac{a}{a}$ and unable to sporulate. The results of tetrad analysis of these hybrids, shown in table 4, confirm the genotype of parent

TABLE 4

Tetrad analysis of triploid strains $X 3 n-1$ and $X 3 n-2$

No. of spores with genes

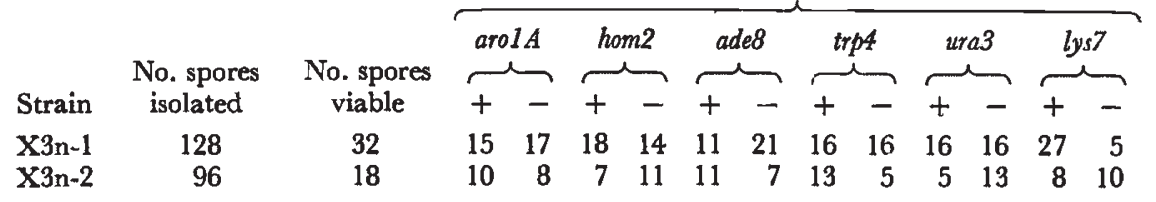


$\mathrm{X} 190 \mathrm{~T}-\mathrm{S}$ as $\frac{\text { ura3 }}{\text { ura3 }} \frac{\text { lys } 7}{+} \frac{\text { aro1A }}{+} \frac{\operatorname{trp4}}{+} \frac{\text { ade8 }}{+} \frac{\text { ade2 }}{\text { ade2 }}$ since segregants of both hybrids which required lysine or tyrosine or tryptophan or adenine (white) were observed. The probable genotypes of hybrids X3n-1 and X3n-2 were therefore as given in Materials and Methods.

\section{(c) Mitotic segregation in the tetraploid strain}

Platings of strain X190T grown in broth by serial transfer produced no white colony which was neither petite nor an adenine-independent revertant. The rate of tetraploid recombination directly to $(a d e 8)^{4}$ was concluded to be very low and unable to be measured by the method of " rate of increase of proportion of recombinants" (Stocker, 1949; Novick and Szilard, 1950; Thornton and Johnston, 1971).

TABLE 5

Segregation ratios for pink sectors X190T-P1, P2, P3

\begin{tabular}{|c|c|c|c|c|c|}
\hline \multirow[b]{2}{*}{ Gene } & \multirow[b]{2}{*}{ Strain } & \multicolumn{4}{|c|}{ No. of asci with segregation ratio $(+:-$} \\
\hline & & $4: 0$ & $3: 1$ & $2: 2$ & $1: 3$ \\
\hline & P1 & 2 & 3 & 1 & 0 \\
\hline \multirow[t]{3}{*}{$\operatorname{aro1A}$} & P2 & 11 & 12 & 0 & 0 \\
\hline & P3 & 23 & 1 & 0 & 0 \\
\hline & P1 & 2 & 3 & 1 & 0 \\
\hline \multirow[t]{3}{*}{ hom 2} & P2 & 9 & 12 & 3 & 0 \\
\hline & P3 & 23 & 1 & 0 & 0 \\
\hline & Pl & 0 & 0 & 5 & 1 \\
\hline \multirow[t]{3}{*}{ ade8 } & P2 & 0 & 0 & 21 & 3 \\
\hline & P3 & 0 & 0 & 23 & 1 \\
\hline & P1 & 0 & 0 & 5 & 1 \\
\hline \multirow[t]{3}{*}{$\operatorname{trp4}$} & P2 & 0 & 0 & 22 & 2 \\
\hline & P3 & 0 & 0 & 23 & 1 \\
\hline & P1 & 4 & 2 & 0 & 0 \\
\hline \multirow[t]{3}{*}{ ura3 } & P2 & 13 & 4 & 7 & 0 \\
\hline & P3 & 17 & 4 & 3 & 0 \\
\hline & P1 & 5 & 1 & 0 & 0 \\
\hline \multirow[t]{2}{*}{ lys7 } & P2 & 17 & 4 & 3 & 0 \\
\hline & P3 & 18 & 5 & 1 & 0 \\
\hline
\end{tabular}

Colonies of strain X190T contained pink sectors, however, and pink colonies were observed when a broth culture of this strain was plated. No attempt was made to measure the rate of production of pink variants because of the ambiguity of classifying some colonies as red or pink. Many pink sectors were, however, clearly distinguishable and cultures were made of three of these and named X190T-PI, P2 and P3. Pink colonies of these three isolates produced white sectors and of a sample of 140 sectors four were adenine-independent revertants, 26 ade 8 recombinants and 110 ade 8 trp4 recombinants. The ratio of double to single recombinants is similar to that obtained for diploid strain X190. Sporulation of these three pink isolates was good and tetrad analysis of each was carried out. The results are shown in table 5 . The numbers of $4: 0,3: 1$, and $2: 2$ segregation ratios for markers ura 3 and lys 7 in all 3 strains and for genes arol $A$ and hom 2 in strains X190T-P1 and -P2 are similar to those for strain X190T. The pink sectors therefore appear to be tetraploid and of identical genotype to 
strain $\mathrm{X} 190 \mathrm{~T}$ at these loci. In all three pink strains, however, genes ade8 and trp4 show only $2: 2$ and $3: 1$ segregation ratios. This suggests that the sectors have genotypes $\frac{(a d e \delta)^{3}}{+} \frac{(t r p)^{3}}{+}$. In addition, the most probable genotype for strain X190T-P3 at the arolA and hom2 loci appears to be aro1A hom 2

$\overline{(+)^{3}} \overline{(+)^{3}}$.

Two tetrads each of strains X190T-P2 and -P3, in which all four spore cultures could themselves sporulate, were subjected to tetrad analysis. The

TABLE 6

Tetrad analysis of two asci of each of strains X190T-P2, P3 (all spore cultures able to sponulate)

Phenotype for gene

\begin{tabular}{|c|c|c|c|c|c|c|c|}
\hline Strain & Ascus & $\operatorname{aro} 1 \mathrm{~A}$ & hom2 & ade8 & $\operatorname{trp4}$ & ura3 & lys 7 \\
\hline \multirow[t]{10}{*}{$-\mathrm{P} 2$} & 1 & - & + & + & + & + & + \\
\hline & & + & - & + & - & - & + \\
\hline & & + & + & - & _ & + & + \\
\hline & & + & + & - & - & + & + \\
\hline & Segregation ratio & $3: 1$ & $3: 1$ & $2: 2$ & $1: 3$ & $3: 1$ & $4: 0$ \\
\hline & 2 & + & + & + & - & + & + \\
\hline & & + & + & + & + & + & + \\
\hline & & + & + & - & - & + & + \\
\hline & & + & + & - & + & + & + \\
\hline & Segregation ratio & $4: 0$ & $4: 0$ & $2: 2$ & $2: 2$ & $4: 0$ & $4: 0$ \\
\hline \multirow[t]{8}{*}{$-\mathrm{P} 3$} & 1 & + & + & - & - & + & + \\
\hline & & + & + & + & + & + & + \\
\hline & & + & + & - & - & + & + \\
\hline & Segregation ratio & $\stackrel{+}{4: 0}$ & $\stackrel{+}{4: 0}$ & $\stackrel{+}{+} \stackrel{+}{2: 2}$ & $\stackrel{+}{2: 2}$ & $4^{+}: 0$ & $4^{+}: 0$ \\
\hline & 2 & + & + & - & - & + & + \\
\hline & & + & + & - & - & + & + \\
\hline & & + & + & + & + & + & + \\
\hline & Segregation ratio & $\stackrel{+}{4: 0}$ & $4: 0$ & $\stackrel{+}{2: 2}$ & $\begin{array}{c}+ \\
2: 2\end{array}$ & $\stackrel{+}{4: 0}$ & $4^{+}: 0$ \\
\hline
\end{tabular}

detailed results of primary analysis of these four tetrads are shown in table 6 and the secondary analysis of the 16 segregant cultures in table 7 . These results confirm the genotypes of pink sectors $\mathrm{P} 2$ and P3 as:

and

$$
\left(\begin{array}{llllll}
(a d e 2)^{4} & \frac{(\text { ade } 8)^{3}}{+} & \frac{(\operatorname{trp} 4)^{3}}{+}
\end{array}\left[\begin{array}{llll}
\frac{\operatorname{aro1A}}{+} & \text { hom } 2 & \frac{\text { ura3 }}{+} & \frac{\text { lys } 7}{+}
\end{array}\right]^{2}\right.
$$

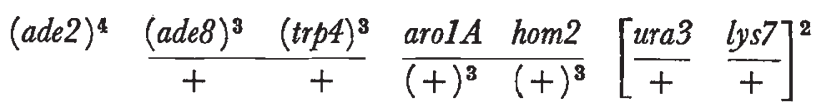

respectively. Clearly pink sectors are tetraploid recombinants for ade8, i.e. $\left[\frac{\text { ade } 8}{+}\right]^{2} \rightarrow \frac{(a d e 8)^{3}}{+}$, and, at times also for $\operatorname{trp4}$ i.e. $\left[\frac{\operatorname{trp} 4}{+}\right]^{2} \rightarrow \frac{(\operatorname{trp} 4)^{3}}{+}$, but apart from the colour change, are not phenotypic segregants. Evidently, gene dose has a quantitative effect upon colour with cells carrying two Ade8 
(wild-type) genes developing more red pigment than cells with only one Ade8 gene. The genotype of sector P3 is surprising as it shows recombination also for the arolA and hom 2 loci, resulting in three wild-type alleles at both loci compared with three mutant alleles for the ade8 and $\operatorname{trp4} 4$ loci. It can only be explained by two recombination events leading to sector P3, occurring either at the same or different mitotic divisions. It is not possible from the analysis of pink sectors to distinguish between reciprocal and nonreciprocal recombination processes. However, analysis of half-sectored colonies of diploid strain X190 has indicated that a high proportion of spontaneous mitotic recombinants is non-reciprocal (Johnston, 1971).

TABLE 7

Segregation ratios of asci of spore cultures (table 6) of strains X190T-P2, P3

Segregation ratio for gene $(+:-)$

\begin{tabular}{|c|c|c|c|c|c|c|c|}
\hline Strain & Ascus & aro $1 A$ & hom 2 & ade 8 & $\operatorname{trp4}$ & ura3 & $l y s 7$ \\
\hline \multirow[t]{2}{*}{$-\mathrm{P} 2$} & ggregate ratio & $\begin{array}{l}0: 4 \\
2: 2 \\
4: 0 \\
2: 2 \\
8: 8\end{array}$ & $\begin{array}{l}2: 2 \\
0: 4 \\
4: 0 \\
2: 2 \\
8: 8\end{array}$ & $\begin{array}{l}2: 2 \\
2: 2 \\
0: 4 \\
0: 4 \\
4: 12\end{array}$ & $\begin{array}{l}4: 0 \\
0: 4 \\
0: 4 \\
0: 4 \\
4: 12\end{array}$ & $\begin{array}{l}4: 0 \\
0: 4 \\
2: 2 \\
2: 2 \\
8: 8\end{array}$ & $\begin{array}{l}2: 2 \\
2: 2 \\
2: 2 \\
2: 2 \\
8: 8\end{array}$ \\
\hline & ggregate ratio & $\begin{array}{l}2: 2 \\
2: 2 \\
2: 2 \\
2: 2 \\
8: 8\end{array}$ & $\begin{array}{l}2: 2 \\
2: 2 \\
2: 2 \\
2: 2 \\
8: 8\end{array}$ & $\begin{array}{l}2: 2 \\
2: 2 \\
0: 4 \\
0: 4 \\
4: 12\end{array}$ & $\begin{array}{l}0: 4 \\
2: 2 \\
0: 4 \\
2: 2 \\
4: 12\end{array}$ & $\begin{array}{l}2: 2 \\
2: 2 \\
2: 2 \\
2: 2 \\
8: 8\end{array}$ & $\begin{array}{l}2: 2 \\
2: 2 \\
2: 2 \\
2: 2 \\
8: 8\end{array}$ \\
\hline$-\mathrm{P3}$ & gregate ratio & $\begin{array}{r}4: 0 \\
2: 2 \\
2: 2 \\
4: 0 \\
12: 4\end{array}$ & $\begin{array}{r}4: 0 \\
2: 2 \\
2: 2 \\
4: 0 \\
12: 4\end{array}$ & $\begin{array}{l}0: 4 \\
2: 2 \\
0: 4 \\
2: 2 \\
4: 12\end{array}$ & $\begin{array}{l}0: 4 \\
2: 2 \\
0: 4 \\
2: 2 \\
4: 12\end{array}$ & $\begin{array}{l}2: 2 \\
2: 2 \\
2: 2 \\
2: 2 \\
8: 8\end{array}$ & $\begin{array}{l}2: 2 \\
2: 2 \\
2: 2 \\
2: 2 \\
8: 8\end{array}$ \\
\hline & gregate ratio & $\begin{array}{r}4: 0 \\
4: 0 \\
2: 2 \\
2: 2 \\
12: 4\end{array}$ & $\begin{array}{r}4: 0 \\
4: 0 \\
2: 2 \\
2: 2 \\
12: 4\end{array}$ & $\begin{array}{l}0: 4 \\
0: 4 \\
2: 2 \\
2: 2 \\
4: 12\end{array}$ & $\begin{array}{l}0: 4 \\
0: 4 \\
2: 2 \\
2: 2 \\
4: 12\end{array}$ & $\begin{array}{l}2: 2 \\
2: 2 \\
2: 2 \\
2: 2 \\
8: 8\end{array}$ & $\begin{array}{l}2: 2 \\
2: 2 \\
2: 2 \\
2: 2 \\
8: 8\end{array}$ \\
\hline
\end{tabular}

Although genetic analysis of white sectors produced by colonies of pink sectors was not performed, it is likely that these white sectors are tetraploid mitotic recombinants of genotype $(a d e 8)^{4}$ or $(\text { ade } 8 \text { trp } 4)^{4}$. Mitotic segregation in strain X190T would then be a two-step process, consisting of recombinational events, (1) $\left[\frac{\text { ade } 8}{t}\right]^{2} \rightarrow \frac{(\text { ade } 8)^{3}}{t}$ and (2) $\frac{(\text { ade } 8)^{3}}{t} \rightarrow{ }^{(a d e 8)^{4}}$.

\section{(d) Mitotic segregation in triploid strains}

Colonies of strain X3n-l produced white sectors whereas those of strain X3n-2 did not. The phenotypes of a sample of 90 white sectors of strain X3n-1 were 4 adenine-independent, 30 adenine-dependent, and 56 adenineand tryptophan-dependent, a similar distribution to that of white sectors of diploid strain X190. Although colonies of strain X3n-2 appeared slightly darker than those of $\mathrm{X} 3 \mathrm{n}-1$, the difference in colour was not clearly distinguishable and probably accounts for the lack of detection of pink sectors 
in colonies of strain X3n-2. These colonies suggest that triploid strain X3n-2 has a similar mitotic stability to tetraploid strain X190T while strain X3n-1 behaves similarly to diploid strain X190.

The strains X3n-1 and X3n-2 were also grown in broth by daily transfers over 18 days. Samples were plated every third day to obtain the proportion of white colonies, which were then tested for adenine dependence and respiratory competence. The proportion of ade8 mitotic recombinants of strain X3n-1 increased linearly with time to be 6.9 per cent. after 18 days (180 generations) equivalent to a rate of recombination of $4 \times 10^{-4}$ per cell generation. This is close to the rate of mitotic recombination of ade 8 in diploid strain X190 (Thornton and Johnston, 1971). With strain X3n-2, however, all white colonies were adenine-independent revertants. As with strain X190T, the rate of mitotic segregation of ade8 was therefore too low to be measured by this method.

\section{Discussion}

The foregoing results show that an autotetraploid of a heterozygous diploid exhibits much less mitotic segregation than the diploid itself. The explanation is simple; two stages of recombination are involved. The first step results in a tetraploid recombinant carrying three mutant and one wild-type alleles. This recombinant, which in the case of the ade 8 locus has a phenotype intermediate between the parent and segregant strains, may then itself undergo recombination to form a tetraploid segregant carrying four mutant alleles.

Mitotic segregation in triploid trains also occurs according to this simple model. The triploid strain carrying two mutant and one wild-type alleles produces mitotic segregants (with three mutant alleles) with a similar frequency to the heterozygous diploid strain. The triploid strain with two wild-type and one mutant alleles behaves similarly to the tetraploid strain, requiring an intermediate recombinant of reciprocal genotype (two mutant, one wild-type alleles) for segregation to occur.

Greater mitotic stability of industrial yeast strains through polyploidy is therefore possible, but is dependent upon the polyploid genotype. Only if there is an increase in the number of wild-type alleles does polyploidy lead to greater stability. The increase in stability is however a large one. For example, the rate of mitotic segregation of the autotetraploid strain or triploid strain with two wild-type alleles is approximately the square of the rate of the diploid strain and therefore several orders of magnitude lower. For segregation of ade8, this means that the polyploid rate is around $10^{-7}$ per division compared with $4 \times 10^{-4}$ for the diploid strain. Polyploid strains carrying additional wild-type alleles should therefore have an advantage over diploid strains in industrial processes which feature extended cultivation of yeast.

\section{Summary}

1. From a diploid strain, a variant was isolated which exhibited a much lower frequency of mitotic segregation at the ade 8 and $\operatorname{trp} 4$ loci than diploid cells. Extensive tetrad analysis showed that the variant was an autotetraploid of the diploid strain. 
2. Mitotic segregation in the tetraploid strain was shown to occur by two stages of recombination: (Step 1) to a recombinant carrying three mutant and one wild-type alleles, and (Step 2) from this recombinant to a segregant with four mutant alleles.

3. Triploid strains with genotypes (a) two wild-type and one mutant alleles, and $(b)$ two mutant and one wild-type alleles were constructed from ascospore segregants of the diploid and tetraploid strains respectively. The rate of mitotic segregation of the latter triploid $(b)$ was similar to that of the diploid, whereas the former triploid (a) behaved similarly to the tetraploid strain.

4. The rate of mitotic segregation of the autotetraploid and the triploid with two wild-type alleles was estimated to be approximately the square of the diploid rate. For ade8 these rates are approximately $10^{-7}$ in the tetraploid compared with $4 \times 10^{-4}$ in the diploid. These polyploid constitutions should have advantageous stability in industrial processes involving prolonged growth of yeast.

Acknowledgment.-We are grateful for the support of a Science Research Council Studentship (to JMM) during this work.

\section{REFERENGES}

Emeis, c. c. 1961. Polyploide Kulturhefen. Proc. Eur. Brew. Conv., Vienna, 105-215.

emEIs, c. c. 1963. Kulturversuche mit polyploiden Hefen. Proc. Eur. Brew. Conv., Brussels, 362-369.

FOGEL, S., AND MORTIMER, R. K. 1970. Fidelity of meiotic gene conversion in yeast. Molec. Gen. Genetics, 109, 177-185.

Johnston, J. R. 1963 . Hybridized yeasts in brewing. Proc. Eur. Brew. Conv., Brussels, $412-$ 421.

Johnston, J. R. 1965. Breeding yeasts for brewing. I. Isolation of breeding strains. F. Inst. Brew., 71, 130-135.

Johnston, J. R. 1971. Genetic analysis of spontaneous half-sectored colonies of Saccharomyces cerevisiae. Genet. Res., 18, 179-184.

Johnston, J. R., AND MACKINNON, J. M. 1966. Mitotic segregation of ade8 in diploid and tetraploid Saccharomyces. Proc. 2nd Symp. Yeasts, Bratislava, 277-285.

Novick, A. A., AND SzILARD, L. 1950. Experiments with the chemostat on spontaneous mutations of bacteria. Proc. nat. Acad. Sci. U.S.A. 36, 708-719.

OGUR, M., AND ST JOHN, R. 1956. A differential and diagnostic plating method for population studies of respiration deficiency in yeast. F. Bact., 72, 500-504.

POMPER, S., DANIELS, K. M., AND MCKEE, D. W. 1954. Genetic analysis of polyploid yeast. Genetics, 39, 343-355.

ROMAN, H. 1956. A system selective for mutations affecting the synthesis of adenine in yeast. C. R. Lab. Carlsberg (Ser. Physiol.), 26, 299-314.

ROMAN, H., PHILlips, M. M., AND SANDs, s. M. 1955. Studies of polyploid Saccharomyces. I. Tetraploid segregation. Genetics, 40, 546-561.

STOCKER, B. A. D. 1949. Measurements of rate of mutation of flagellar antigenic phase in Salmonella typhimurium. 7. Hyg., Camb., 47, 398-413.

THORNTON, R. J., AND JOHNSTON, J. R. 1971. Rates of spontaneous mitotic recombination in Saccharomyces cerevisiae. Genet. Res., 18, 147-151. 